http://jmscr.igmpublication.org/home/ ISSN (e)-2347-176x ISSN (p) 2455-0450 crossref DOI: https://dx.doi.org/10.18535/jmscr/v7i8.73

\title{
Comparative Efficacy of Oral Tranexamic Acid and Trans-epidermal Delivery of Tranexamic Acid by Micro-Needling in Melasma
}

\author{
Authors \\ Mudita Gupta ${ }^{1}$, Saru Thakur ${ }^{2 *}$, Shikha Sharma ${ }^{3}$, GR Tegta ${ }^{4}$, Ghanshyam Verma \\ ${ }^{1}$ Assistant Professor, ${ }^{2,3}$ Post graduate student, ${ }^{4}$ Professor and Head, ${ }^{5}$ Associate Professor \\ Deptt. of Dermatology, Venereology and Leprosy, Indira Gandhi Medical College, Shimla, \\ Himachal Pradesh \\ *Corresponding Author
}

Saru Thakur

Deptt. of Dermatology, Leprosy and Venereology, Indira Gandhi Medical College, Shimla,

Himachal Pradesh, India

\begin{abstract}
Background: Melasma is an acquired hyperpigmentary disorder of photo-exposed skin. It leads to lowered self-esteem. Treatment of melasma is not very rewarding and demands a multimodal approach. Tranexamic acid (TXA) acts as an inhibitor of melanin synthesis. There are multiple methods of delivering this drug to the site of melanization.
\end{abstract}

Aims: To compare the therapeutic efficacy and safety of tranexamic acid administered by microneedling and oral route in patients of melasma.

Methods: A prospective randomized study was conducted in 30 consecutive patients of melasma, who were enrolled into two groups; group A (received TxA by microneedling) and group B (oral TxA). The baseline details of melasma were recorded and MASI was recorded at 4,8 and 12 weeks.

Results: Females outnumbered males in a ratio of 4:1.There was no significant difference in the two groups on the basis of sex, age, duration of melasma, mean MASI score at baseline and pattern of melasma. Reduction in MASI score was more in oral TxA group but the difference was not statistically significant(5.89 vs 4.25). More than $50 \%$ improvement was seen in $40 \%$ patients in group B and $20 \%$ in group A.

Conclusion: Tranexamic acid is an effective treatment of melasma, the route of administration does not significantly alter the outcome.

Keywords: Melasma, tranexemic acid, oral, microneedling

\section{Introduction}

Melasma (Greek 'melas'- black) is a common, acquired hyperpigmentation that occurs in sunexposed areas. It is seen in all racial groups and is more common in subjects with darker skin phototypes. ${ }^{1}$ Melasma usually appears at a mean age of 30 years and causes significant psychosocial stress and embarrassment. The exact pathogenesis of melasmais not known. Various factors implicated are exposure to ultraviolet (UV) radiation, pregnancy, contraceptive pills, hormone replacement therapy, cosmetics, phototoxic and antiseizure medications. ${ }^{2}$ UV irradiation also leads to increase in dermal vasculature with upregulation of proangiogenic factors (vascular endothelial growth factor (VEGF), basic fibroblast growth 
factor and interleukin-8). ${ }^{3,4}$ Treatment for melasma is based on decreasing melanocyte proliferation, inhibiting formation of melanosomes or promoting their degradation. Different hypopigmenting agents used are hydroquinone, retinoic acid, kojic acid, azelaic acidetcwhich act by decreasing melanin synthesis. Peeling agents like glycolic acid, trichloroacetic acid, salicylic acid, lactic acid act by increasing degradation of pigmentary cells. Different physical modalities like lasers, dermabrasion also increase degradation of melanocytes.

Tranexamic acid (TxA; trans-4aminomethylcyclohexanecarboxylic acid) is antifibrinolyticagent that inhibitsthe interaction between plasminogen and keratinocyte, thus decreasing the tyrosinase activity leading to decreased melanin synthesis from the melanocytes. TxAcan be used orally, intravenously, topically (liposome formulations), intradermally by microinjection, or trans-epidermally by micro needling (mesotherapy). ${ }^{5}$ The superiority of one method over the other is not well documented. In this study, we evaluated the comparative efficacy of two treatment routes of TxA i.e.trans-epidermal delivery(by micro-needling) and oral route.

\section{Aims and Objectives}

To compare the therapeutic efficacy and safety of tranexamic acid administered by microneedling and oral route in patients of melasma.

\section{Methods}

A prospective randomized trial was conducted in a tertiary care center. A total of 30 consecutive patients with melasma with Fitzpatrick skin type III and IV were enrolled after informed consent. Clinical details, including demograpghic (age and sex), disease duration, and clinical type (epidermal/dermal) and distribution were recorded. Patients who had pre-existing bleeding, coagulation, thromboembolic, psychological disorders and who were pregnant, lactating or on oral contraceptives were excluded. Platelet count, bleeding time, clotting time and prothrombin index (international normalized ratio; INR) were measured at baseline and at the end of the 12-week study period. The enrolled patients were assigned alternatively to group A (micro-needling TXA) or group B (oral TxA). A $4 \mathrm{mg} / \mathrm{ml}$ solution of TxA was prepared and instilled by micro-needling every 4 weeks in Group A while $250 \mathrm{mg}$ twice daily oral TxA was given for 12 weeks in group B.

The micro needles used were a ZGTS dermaroller studded with 192 fine needles of titanium of needle length $1.5 \mathrm{~mm}$ and diameter $0.25 \mathrm{~mm}$. These needles can penetrate to a depth of 0.1 to $1.3 \mathrm{~mm}$ according to the pressure applied. The skin was stretched and micro needling was carried out in vertical, horizontal and both diagonal directions for about four to five times followed by application of TxA solution. The procedure was repeated three times in one sitting. Photoprotection was advised. Sessions were repeated at 4,8 and 12 weeks. In group B, $250 \mathrm{mg}$ of TxA was given orally twice a day for 12 weeks. All patients concurrently used the same sunscreen in both the groups.

To assess response, melasma area and severity index scores (MASI) were calculated at the beginning and at 4,8 and 12 weeks. MASI was calculated using Kimbrough-Green et al's technique. Combined assessment of melasma darkness and homogeneity was made depending on the surface area of face involved. Forehead (F), right malar region (MR), left malar region (ML) corresponded to $30 \%$ of face each and chin (C) to $10 \%$ of the total face.

Subjective response to treatment, according to patient, was graded at the end of the study as follows: no response, no improvement; mild response, $<25 \%$ improvement; moderate response, $25 \%-<50 \%$ improvement; good response, $50 \%-$ $<75 \%$ improvement and excellent response, $>75 \%$ improvement. A record was kept of any side effect occurring in the patients.

Statistical analysis was completed using z-test. A ' $p$ ' value was calculated at $5 \%$ level and value less than 0.05 was considered statistically significant. 


\section{Results}

Thirty consecutive patients with melasma were enrolled for the study attending outpatient clinic of Dermatology, Venereology and Leprosy department of our institute after obtaining informed consent. There were 15 patients in Group-A (micro needling TXA) and 15 patients in Group-B(oral TxA). The data was analyzed for various parameters before and after treatment. The demographic and pretreatment profile of the patients was as shown in table 1 .

Table-1: Pretreatment characteristics of all patients

\begin{tabular}{|l|c|c|}
\hline Characteristics & $\begin{array}{c}\text { Number of } \\
\text { patients } \\
(\mathbf{n}=30)\end{array}$ \\
\hline \multirow{2}{*}{ Gender } & Females & $24(80 \%)$ \\
\cline { 2 - 3 } & Males & $6(20 \%)$ \\
\hline \multirow{2}{*}{ Age } & Range (years) & $21-45$ \\
\cline { 2 - 3 } & Mean (years) & 34.4 \\
\hline \multirow{2}{*}{$\begin{array}{l}\text { Duration of } \\
\text { Melasma }\end{array}$} & Range (years) & $0.5-7$ \\
\cline { 2 - 3 } MASI Score & Mean (years) & 2.5 \\
\cline { 2 - 3 } & Range & $3.2-28.4$ \\
\hline
\end{tabular}

Group A included 13 female patients while in Group $\mathrm{B}$ there were 11 and the difference was statistically insignificant ( $\mathrm{p}$ value>0.05). The mean age in Group A was 32 years while that in Group B was 35.2 years ( $p$ value $>0.05$ ). The mean duration of melasma was 3.0 years in Group A and 2.8 years in Group B ( $\mathrm{p}$ value $>0.05$ ). The mean MASI score in both the groups was $8.73 \pm 2.76$ and $9.27 \pm 3.02$ in Group-A and Group-B, respectively. There was no statistically significant difference in mean MASI score in both the groups. Majority of the patients, $19(63.3 \%)$ had centrofacial pattern and 10(33.3\%) patients had malar pattern. Mandibular pattern was noted in one $(3.3 \%)$ patient only (Table 2 ). On Wood's lamp examination, majority of the patients had mixed pattern $20(66.6 \%)$ (Table 2).

Table-2: Patterns of Melasma in two groups

\begin{tabular}{|c|c|c|c|c|}
\hline \multicolumn{2}{|c|}{ Patterns of Melasma } & \multirow{2}{*}{$\begin{array}{c}\text { Group A } \\
(n=15)\end{array}$} & \multirow{2}{*}{$\begin{array}{c}\begin{array}{c}\text { Group } \\
\text { B } \\
(\boldsymbol{n}=\mathbf{1 5})\end{array} \\
9(60 \%)\end{array}$} & \multirow{2}{*}{$\begin{array}{c}\begin{array}{c}\text { Total } \\
(\boldsymbol{n}=\mathbf{3 0})\end{array} \\
19(63.3 \%)\end{array}$} \\
\hline \multirow{3}{*}{$\begin{array}{l}\text { Clinical } \\
\text { patterns }\end{array}$} & Centrofacial & & & \\
\hline & Malar & $4(26.6 \%)$ & $6(40 \%)$ & $10(33.3 \%)$ \\
\hline & Mandibular & $1(6.6 \%)$ & 00 & $1(3.3 \%)$ \\
\hline \multirow{3}{*}{$\begin{array}{l}\text { Patterns } \\
\text { under } \\
\text { Wood's } \\
\text { Lamp }\end{array}$} & Epidermal & $2(13.3 \%)$ & $3(20 \%)$ & $5(16.6 \%)$ \\
\hline & Dermal & $2(13.3 \%)$ & $3(20 \%)$ & $5(16.6 \%)$ \\
\hline & Mixed & $\begin{array}{c}11 \\
(73.3 \%)\end{array}$ & $9(60 \%)$ & $20(66.6 \%)$ \\
\hline
\end{tabular}

MASI score in the two groups was calculated at baseline and subsequently recorded at 4,8 and 12 weeks (Table 3)

Table-3: Comparison of MASI score at each follow up visit

\begin{tabular}{|l|c|c|}
\hline Follow up & $\begin{array}{c}\text { Group A } \\
(\boldsymbol{n}=\mathbf{1 5})\end{array}$ & $\begin{array}{c}\text { Group B } \\
(\boldsymbol{n}=\mathbf{1 5})\end{array}$ \\
\hline Baseline & $8.73 \pm 2.76$ & $9.27 \pm 3.02$ \\
\hline $\begin{array}{l}\text { First Follow up at 4 } \\
\text { weeks }\end{array}$ & $6.95 \pm 2.14$ & $6.74 \pm 2.56$ \\
\hline $\begin{array}{l}\text { Second Follow up at 8 } \\
\text { weeks }\end{array}$ & $5.02 \pm 1.98$ & $4.56 \pm 1.86$ \\
\hline $\begin{array}{l}\text { Third Follow up at 12 } \\
\text { weeks }\end{array}$ & $4.48 \pm 1.64$ & $3.38 \pm 1.46$ \\
\hline
\end{tabular}

Mean MASI in both the groups decreased at each visit. Subjective response as appreciated by patients was as observed in table 4. There were total of $8(26.6 \%)$ patients who had more than $50 \%$ improvement.

Table 4: Comparative response in two groups

\begin{tabular}{|l|c|c|}
\hline $\begin{array}{l}\text { Response } \\
(\%)\end{array}$ & $\begin{array}{c}\text { Group A } \\
\mathrm{n}=15\end{array}$ & $\begin{array}{c}\text { Group B } \\
\mathrm{N}=15\end{array}$ \\
\hline$<25$ & 3 & 2 \\
\hline $25-50$ & 10 & 7 \\
\hline $50-75$ & 2 & 4 \\
\hline$>75$ & 0 & 2 \\
\hline
\end{tabular}

There were no significant adverse effects in either group. One patient in micro needling group developed a small hematoma that gradually subsided on its own. Mild pain during micro needling was complained by $5(33.3 \%)$ patients. There was a single patient who complained of epigastric discomfort in group B.

\section{Discussion}

Melasma is an acquired hypermelanosis commonly involving the face, leading to significant cosmetic and psychological morbidity. The reported incidence is not exactly known but account for 0.25 to $4 \%$ of the patients seen in any dermatology clinic. ${ }^{6}$ There is no treatment of melasma which is universally effective and multimodal therapy is usually tried. The targets of therapy are to decrease melanocyte proliferation, inhibit formation of melanosomes and promote their degradation. Tyrosinase inhibitors can be competitive (hydroquinone, azelaic acid, arbutin, deoxyarbutin, 
aloesin, kojic acid, flavanoids, saponin, oregonin and yohimbine) or non competitive (Glabiridin and hydroxystilbenes). ${ }^{7} \quad$ Newer tyrosinase inhibitors diaryl propane, hydroxyl phenolnaphthol, calycosin are under trial. ${ }^{8}$ Various physical modalities causing increased degradation of melanocytes for melasma include chemical peels using lactic acid, glycolic acid and trichloroacetic acid, laser treatments (pulsed carbon dioxide laser, Q-switched ruby laser, Qswitched Alexandrite laser, erbium:yttriumaluminum-garnet (Er:YAG) laser, Fraxel laser and intense pulsed light (IPL) treatment. ${ }^{9}$ Role of TxA in melasma was incidentally observed by Sadako while treating a patient of chronic urticaria. ${ }^{10} \mathrm{TxA}$ was used for the first time in melasma by Nijorin. ${ }^{11}$ Epidermal keratinocytes have VEGF receptors which interact with proangiogenic factors and release mediators (plasminogen and metabolites of arachidonic acid).The plasmin inhibitory effect of tranexamic acid will affect keratinocyte function and activation of melanocytes by injured keratinocytes leading to improvement of melasma and its prevention from recurrence.

TxA can be given by different routes, the benefit of one over the other has not been properly evaluated. Common side effects with oral TxA include nausea, vomiting and diarrhea and rarely disturbances in color vision, anaphylactic shock, skin reaction, orthostatic hypotension, acute renal cortical necrosis, thromboembolism, pulmonary embolism and myocardial infarction.

TxA leads to significant reduction in MASI as seen in our study and previous studies. The preferred route of administration of TxA has also been studied. Budamakuntla et al observed more improvement with micro needling than by microinjection $(44.41 \%$ vs $35.72 \%)$ and microinjections were found to be superior than topical application. ${ }^{12}$ Administration of TxA by microinjection was found superior to topical TxA. ${ }^{13}$ Sharma et al concluded that TxA is an effective treatment for melasma and the route of administration does not alter the effectivity. ${ }^{14} \mathrm{We}$ also observed that there is no significant difference in response when drug is administered by microneedling or by oral route. Like other studies there were no significant side effects observed in any group.

\section{Conclusion}

Tranexamic acid is an effective treatment for melasma. Route of administration does not determine the clinical efficacy of the drug.

\section{Sources of support and sponsorship: Nil. \\ Conflicts of interest: Nil.}

\section{References}

1. Katsambas AD, Stratigos AJ, Lotti TM. Melasma. In: Andreas DK, Lotti TM, eds. European Handbook of Dermatological Treatments. 2nd ed. Springer; 2003. p. 336.

2. Grimes PE. Melasma: etiologic and therapeutic considerations. Arch Dermatol1995;131:1453-7.

3. Gilchrest BA, Fitzpatrick TB, Anderson RR, Parrish JA. Localization of melanin pigmentation in skin with Wood's lamp. Br J Dermatol 1977;96:245-8.

4. Menter A. Rationale for the use of topical corticosteroids in melasma. $J$ Drugs Dermatol 2004;3:169-74.

5. Maeda K, Naganuma M. Topical trans-4aminomethylcyclohexanecarboxylic acid prevents ultraviolet radiation-induced pigmentation. J PhotochemPhotobiol 1998;47:136-41.

6. Sivayathorn A. Melasma in Orientals. Clin Drug Investig1995;10:24-40.

7. Romero C, Aberdam E, Larnier C, Ortonne JP. Retinoic acid as modulator of UVB-induced melanocyte differentiation. J Cell Sci 1994;107:1095-103.

8. Perez-Bernal A, Munoz-Perez MA, Camacho F. Management of facial hyperpigmentation. Am J ClinDermatol 2000;1:261-8. 
9. Cho HH, Choi M, Cho S, Lee JH. Role of oral tranexamic acid in melasma patients treated with IPL and low fluence QS Nd:YAG laser. J Dermatol Treat 2013;24:292-6.

10. Sadako N. Treatment of melasma with tranexamic acid. The Clin Rep 1979;13:3129-31.

11. Nijor T. Treatment of melasma with tranexamic acid. Clin Res1979;13:312931.

12. Budamakuntla L, Loganathan E, Suresh DH, Shanmugam S, Suryanarayan S, Dongare A, et al. Microinjections and microneedling in patients with melasma. J CutanAesthetSurg 2013;6:139-43.

13. Liu H, Kou CC, Yeung CW. Effectiveness of tranexamic acid in treating melasma and observation of its safety (Chinese). Chin J Med AesthCosmet 2005;11:361-3.

14. Sharma R, MahajanVK, MehtaKS, Chauhan PS, Rawat R, Shiny TN. Therapeutic efficacy and safety of oral tranexamic acid and that of tranexamic acid local infiltration with microinjections in patients with melasma: a comparative study. Clin and ExpDermatol 2017;1:1-17. 